Argonne

ANL-20/18

\title{
Conversion of Uranium Metal to Uranyl Sulfate Solution
}

Chemical \& Fuel Cycle Technologies Division 


\begin{abstract}
About Argonne National Laboratory
Argonne is a U.S. Department of Energy laboratory managed by UChicago Argonne, LLC under contract DE-AC02-06CH11357. The Laboratory's main facility is outside Chicago,

at 9700 South Cass Avenue, Lemont, Illinois 60439. For information about Argonne

and its pioneering science and technology programs, see www.anl.gov.
\end{abstract}

\title{
DOCUMENT AVAILABILITY
}

Online Access: U.S. Department of Energy (DOE) reports produced after 1991 and a growing number of pre-1991 documents are available free at OSTI.GOV (http://www.osti.gov/),

a service of the US Dept. of Energy's Office of Scientific and Technical Information.

Reports not in digital format may be purchased by the public from the National Technical Information Service (NTIS):

U.S. Department of Commerce

National Technical Information Service

5301 Shawnee Road

Alexandria, VA 22312

www.ntis.gov

Phone: (800) 553-NTIS (6847) or (703) 605-6000

Fax: (703) 605-6900

Email: orders@ntis.gov

Reports not in digital format are available to DOE and DOE contractors from the Office of Scientific and Technical Information (OSTI):

U.S. Department of Energy

Office of Scientific and Technical Information

P.O. Box 62

Oak Ridge, TN 37831-0062

www.osti.gov

Phone: (865) 576-8401

Fax: (865) 576-5728

Email: reports@osti.gov

\section{Disclaimer}

This report was prepared as an account of work sponsored by an agency of the United States Government. Neither the United States Government nor any agency thereof, nor UChicago Argonne, LLC, nor any of their employees or officers, makes any warranty, express or implied, or assumes any legal liability or responsibility for the accuracy, completeness, or usefulness of any information, apparatus,

product, or process disclosed, or represents that its use would not infringe privately owned rights. Reference herein to any specific commercial product, process, or service by trade name, trademark, manufacturer, or otherwise, does not necessarily constitute or imply its endorsement, recommendation, or favoring by the United States Government or any agency thereof. The views and opinions of document authors expressed herein do not necessarily state or reflect those of the United States Government or any agency thereof, Argonne National Laboratory, or UChicago Argonne, LLC. 
ANL-20/18

\section{Conversion of Uranium Metal to Uranyl Sulfate Solution}

by

Thomas Brossard, James Byrnes, and Peter Tkac

Chemical \& Fuel Cycle Technologies Division, Argonne National Laboratory

March 2020 



\section{CONTENTS}

ABSTRACT

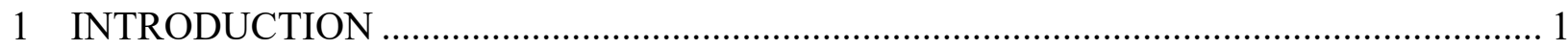

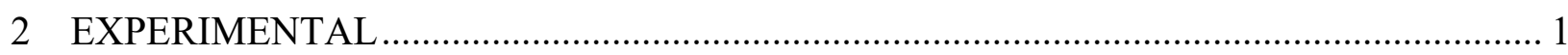

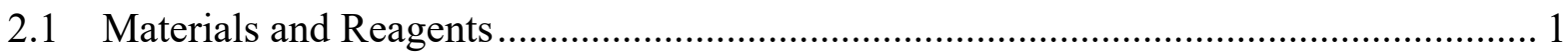

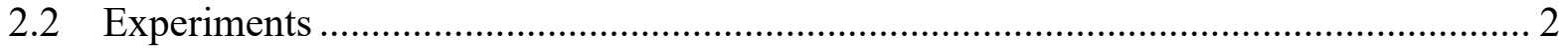

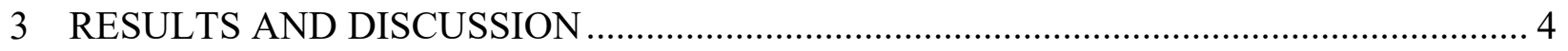

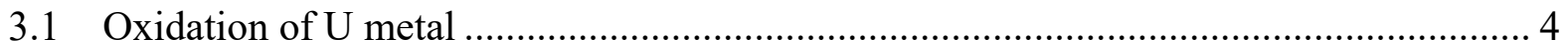

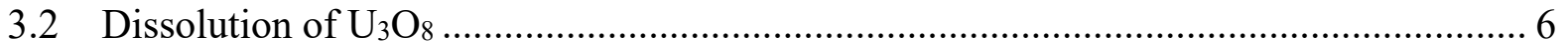

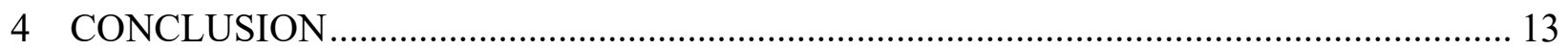

\section{FIGURES}

1 DU plates (left) and LEU pellets (right) used for the oxidation experiments.......................... 3

2 Muffle furnace used for the oxidation of uranium (left) and a batch of uranium post-oxidation (right) in the custom quartz beaker................................................................ 4

3 A 300-g batch of uranium mid-oxidation (left) and the completely oxidized batch

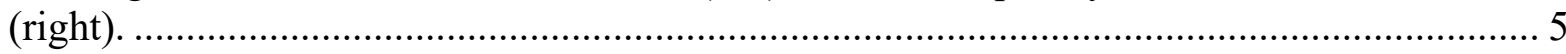

4 Powder X-ray diffraction analysis for the 300 -g batches after oxidation................................. 6

5 Bottom of the dissolution apparatus (left); top of the apparatus (right), with the thermocouple connections and condenser.

6 The beginning of the dissolution of uranium immediately after sulfuric acid was added to the hydrogen peroxide and uranium. The temperature quickly reached $99^{\circ} \mathrm{C}$, and the reaction at this stage was extremely vigorous.................................................. 8

7 A typical temperature profile of a dissolution experiment. .................................................... 8

8 The transition from charcoal black to a gray/green color and a thickening of the solution, starting at $\sim 21 \mathrm{~min}$, is shown above. The temperature of the reaction also started dropping at this point, and heat was applied. 


\section{FIGURES (CONT.)}

9 Approximately 35 minutes into the experiment, the reaction settled down from the vigorous stage, the solution turned more yellow, took on a foamy consistency, and started to "breathe."

10 The foamy mixture transitioned to a more traditional liquid 40 to 45 minutes into the experiment and began to clear.

11 The solution turned completely clear and became the desired uranyl sulfate solution after reacting for approximately an hour.

12 A small amount of residue left behind from the dissolution process................................. 12

\section{TABLES}

1 Amounts of uranium, hydrogen peroxide and sulfuric acid used for conversion of U-metal to uranyl sulfate.

2 Particle size results from the batches of oxidized DU with a comparison to a batch of oxidized LEU.

3 Reaction times for the dissolution of $\mathrm{U}_{3} \mathrm{O}_{8}$ in hydrogen peroxide after the addition of sulfuric acid to the vessel. 


\begin{abstract}
Experiments involving conversion of uranium (U) metal to $\mathrm{U}_{3} \mathrm{O}_{8}$, followed by dissolution to form uranyl sulfate solution, were performed with batches of up to $300 \mathrm{~g}$ of $\mathrm{U}$ metal. The focus was to identify major $\mathrm{U}$ species formed during the oxidation process, determine the particle size distribution of the uranium oxide product, and identify the size of the dissolution vessel needed to accommodate the exothermic reaction during the conversion of $\mathrm{U}_{3} \mathrm{O}_{8}$ to uranyl sulfate using $30 \%$ hydrogen peroxide and $\mathrm{H}_{2} \mathrm{SO}_{4}$. The information obtained in this study will be used for designing full-scale processes to convert kilogram quantities of $\mathrm{U}$ metal to uranyl sulfate solution with a concentration of $300 \mathrm{~g} \mathrm{U} / \mathrm{L}$.
\end{abstract}

\title{
1 INTRODUCTION
}

Argonne National Laboratory, with support from DOE's National Nuclear Security Administration Office of Material Management \& Minimization, is helping SHINE Medical Technologies in developing domestic production of Mo-99. SHINE is planning to produce Mo-99 by fission of low-enriched uranium-235 (LEU) in a subcritical aqueous solution using accelerator-based neutron generation. ${ }^{1}$ SHINE's subcritical system can contain $\sim 250 \mathrm{~L}$ of LEU solution, and several units may be implemented. In order to prepare a large volume of uranyl sulfate solution, the process of conversion of $U$ metal to oxide and uranyl sulfate solution needs to be well understood and optimized. The full-scale dissolution setup should be able to process up to $\sim 600 \mathrm{~g}$ of $\mathrm{U}$ per batch, and have sufficient head space to contain the reaction. Here we report results on conversion of 50-g and 300-g U batches to uranyl sulfate.

\section{EXPERIMENTAL}

\subsection{MATERIALS AND REAGENTS}

All reagents listed were used as received unless specified in the text.

Nitric Acid - TraceMetal Grade was purchased from Fisher Chemical (Part \# A509P212). Sulfuric acid was purchased from Sigma-Aldrich (Part \# 320501-2.5L).

\footnotetext{
${ }^{1}$ S. Chemerisov, G.F. Vandegrift, "Mini-SHINE/MIPS Experiment," Argonne National Laboratory Report ANL/CSE-14/2, September 2011.
} 
$30 \%$ hydrogen peroxide solutions from three suppliers were tested:

- Hydrogen Peroxide Certified ACS, Fisher (Part \# H325-500)

- Hydrogen Peroxide GR ACS, Millipore (Part \# HX0635-2)

- Hydrogen Peroxide ACS reagent, Acros Organics (Part \# 41188-5000)

These hydrogen peroxides were chosen because they were described on their certificates of analysis as $30 \%$ high-purity hydrogen peroxide with no chemical stabilizers present, and were readily available in large quantities.

If needed, $18.2 \mathrm{M} \Omega \cdot \mathrm{cm}$ deionized water was used for all washing and dilution steps.

\subsection{EXPERIMENTS}

Multiple oxidation experiments were performed using depleted uranium (DU) at scales of $\sim 50$ and $\sim 300 \mathrm{~g}$, and are summarized in Table 1 .

TABLE 1 Amounts of uranium, hydrogen peroxide and sulfuric acid used for conversion of $U$-metal to uranyl sulfate.

\begin{tabular}{|c|c|c|c|c|}
\hline \multirow[b]{2}{*}{ Batch } & \multirow{2}{*}{$\begin{array}{l}\text { Initial Mass } \\
\text { Uranium (g) }\end{array}$} & \multirow{2}{*}{$\begin{array}{c}\text { Final Mass } \\
\mathrm{U}_{3} \mathrm{O}_{8}(\mathrm{~g})\end{array}$} & \multicolumn{2}{|c|}{ Volume Added } \\
\hline & & & $\mathrm{H}_{2} \mathrm{O}_{2}(\mathrm{~mL})$ & $\mathrm{H}_{2} \mathrm{SO}_{4}(\mathrm{~mL})$ \\
\hline 1 & 41.3 & 48.6 & 252.0 & 10.3 \\
\hline 2 & 41.5 & 50.3 & 222.0 & 10.4 \\
\hline 3 & 36.9 & 44.9 & 201.0 & 9.2 \\
\hline 4 & 42.8 & 50.4 & 282.0 & 10.7 \\
\hline 5 & 42.1 & 51.2 & 255.0 & 10.0 \\
\hline 6 & 37.1 & 44.5 & 228.0 & 10.0 \\
\hline A & 309.2 & 364.2 & 1712.0 & 77.3 \\
\hline B & 286.6 & 337.4 & 1580.0 & 71.7 \\
\hline $\mathrm{C}$ & 289.9 & 347.3 & 1673.0 & 72.5 \\
\hline
\end{tabular}

These dissolution experiments were performed in a vessel that was custom-made in the Argonne glass shop with parts obtained from ChemGlass. The dissolution vessel was assembled by joining a reaction vessel (CG-1920-02) to a section of 10-cm-ID glass pipe. This assembly rested in a heating mantle (CG-10007-10) and was closed at the top with a 4-neck reaction vessel lid (CG-1941-02). The lid was secured with a clamp (CG-141-02) and three of the ports in the reaction lid were occupied. The first held a high-efficiency condenser (CG-1215-01), while two others were used for SS thermocouples that measured 1/8" wide and 40" long (Omega part \# CASS-18U-40-DUAL) with specially adapted stoppers with pass-through openings (CG-1042-E$01)$. The final port was sealed with a normal glass stopper and used for additions and rinsing the 
walls of the vessel when necessary. One thermocouple was attached to a J-KEM controller for temperature control and over-temperature protection, while the second was connected to a data logger to record temperature profiles during the experiments.

Uranium metal was oxidized into uranium oxides by heating in the presence of oxygen. The muffle furnace was set to a starting temperature of $450^{\circ} \mathrm{C}$ and kept at this temperature for approximately 2 hours. After that, the temperature was increased each hour incrementally from $450^{\circ} \mathrm{C}$ to $600^{\circ} \mathrm{C}$ to $720^{\circ} \mathrm{C}$ and then to $820^{\circ} \mathrm{C}$. The $\mathrm{U}$ baked at $820^{\circ} \mathrm{C}$ for approximately 4 hours to complete the oxidation. The muffle furnace was then turned off and the material was allowed to cool overnight. The final stage of heating ensured that other uranium oxides such as $\mathrm{UO}_{3}$ and $\mathrm{UO}_{2}$ decomposed or were converted to $\mathrm{U}_{3} \mathrm{O}_{8}$. Any oxygen lost from heating $\mathrm{U}_{3} \mathrm{O}_{8}$ above $800^{\circ} \mathrm{C}$ was rapidly replaced upon cooling.

The final uranium oxide product identity was confirmed by analysis with a Siemens D5000 X-Ray Diffractometer (XRD). The XRD program ran from 5 to 70 degrees with a step size of 0.01 and a dwell time of 10 seconds at each step while both axes were scanned with a sample spin rate of 30 RPM. The diffraction patterns were compared to the instrument database and literature to positively identify each sample.

First, 50-g batches of U were processed using DU and LEU metal material. These tests were focused on determining the particle size distribution of $\mathrm{U}_{3} \mathrm{O}_{8}$ particles obtained after oxidation of $U$ metal from different materials. DU metal was in the form of metal foil, while LEU material was in the form of U-metal pellets (Figure 1).

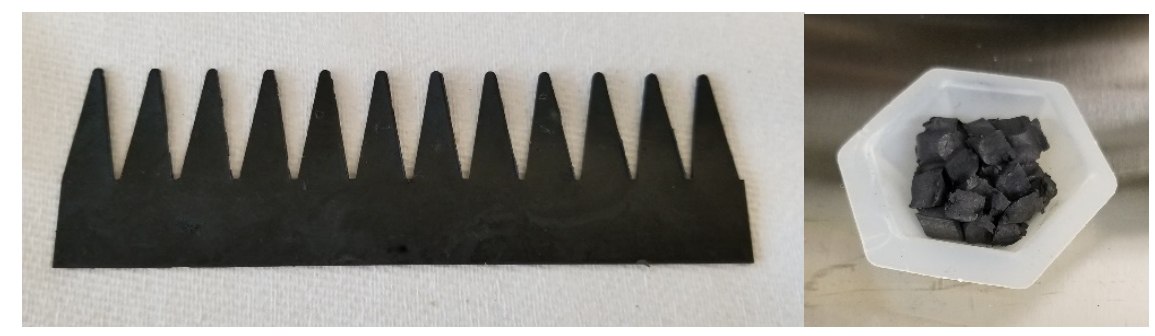

FIGURE 1 DU plates (left) and LEU pellets (right) used for the oxidation experiments.

Particle sizes of the oxidized $U$ were determined by using sieves with various mesh sizes in a Meinzer II sieve shaker (VWR, Part \# 47732-822). Each sample was shaken in the sieve for $40 \mathrm{~min}$ and the amount of material that passed through the sieve was weighed after each step. Mesh sizes of 40, 140 and 230 were used for the sorting, corresponding to $400 \mu \mathrm{m}, 105 \mu \mathrm{m}$, and $63 \mu \mathrm{m}$, respectively. Dissolution of 50 -g $\mathrm{U}$ batches converted to $\mathrm{U}_{3} \mathrm{O}_{8}$ was performed in a $1-\mathrm{L}$ beaker by addition of $30 \%$ hydrogen peroxide followed by addition of sulfuric acid (Table 1).

For large-scale tests using 300-g batches of DU, the dissolution was performed by adding the amount of $30 \%$ hydrogen peroxide found in Table 1 to the oxidized $\mathrm{DU}\left(\mathrm{U}_{3} \mathrm{O}_{8}\right)$. Next, approximately $70 \mathrm{~mL}$ of concentrated sulfuric acid was added to the dissolution vessel. The 
temperature was measured and recorded during the experiment with a temperature logger and a temperature controller was used when the heating mantle was needed to keep the reaction vessel at $95^{\circ} \mathrm{C}$. Once the reaction was completed, the solution was allowed to cool before collection.

\section{RESULTS AND DISCUSSION}

\subsection{OXIDATION OF U METAL}

Six 50-g batches of DU metal plates and one 50-g batch of LEU metal pellets (Figure 1) were converted to $\mathrm{U}_{3} \mathrm{O}_{8}$ by heating. The $\mathrm{U}$ was placed in a custom quartz beaker with a handle and baked at ramping temperatures until $820^{\circ} \mathrm{C}$ was reached, and the material was allowed to bake for 4 hours. It was noted during the baking of the material that the initial phase was exothermic. This was noted because the temperature of the muffle furnace reached over $500^{\circ} \mathrm{C}$ during the initial setting at $450^{\circ} \mathrm{C}$ and remained there for approximately 30 minutes. The muffle furnace used for the experiments and one of the completed oxidations can be seen in Figure 2.

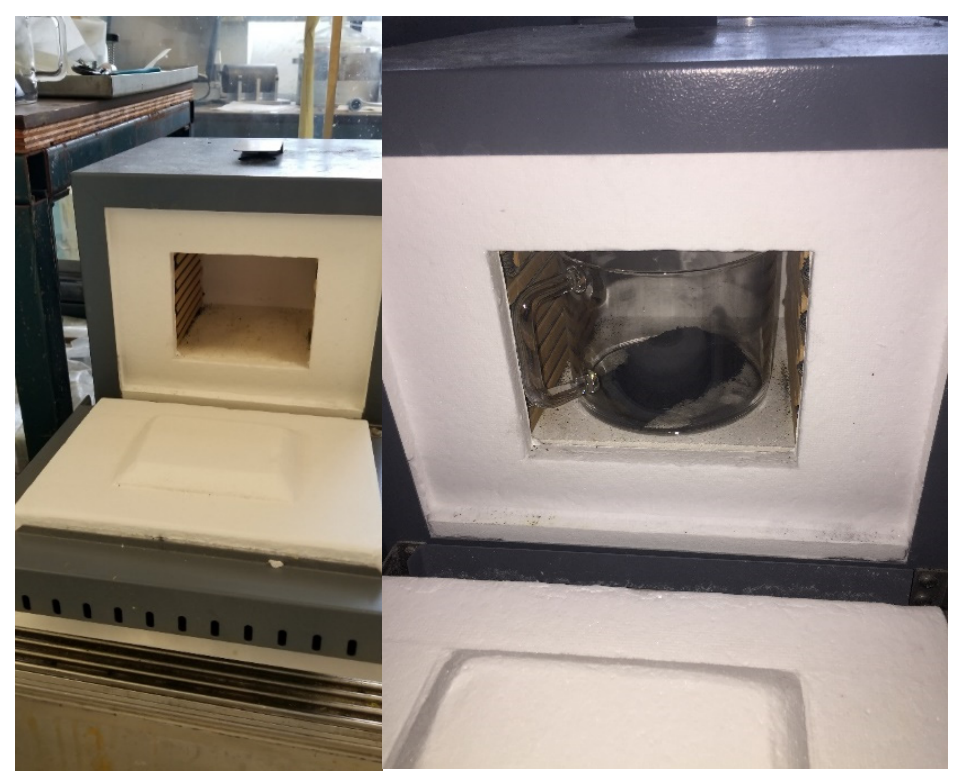

\section{FIGURE 2 Muffle furnace used for the oxidation of uranium (left) and a batch of uranium post-oxidation (right) in the custom quartz beaker.}

Another observation noted while baking the U during the oxidation experiments was that sufficient volume is necessary for the $U$ to expand during the process. The plates shown in Figure 1 expand to the oxidized uranium powder depicted in Figure 3. If the container is too small, there is potential for the DU powder to be spread while removing the container from the muffle furnace, or to spill over into the furnace during oxidation. 
After the oxidation of the DU plates or LEU pellets, the particle size distribution was analyzed. The results from these experiments are listed in Table 2 . The results showed that the particle size distribution varied only slightly between trials when the experiments were performed identically. The particle size distributions obtained after oxidation of the DU metal plates and LEU metal pellets (Table 2) are very similar, indicating that the particle size does not vary much when the starting point is $\mathrm{U}$ metal. Samples were taken from each batch and analyzed by X-ray diffraction (XRD); the results are shown in Figure 4.

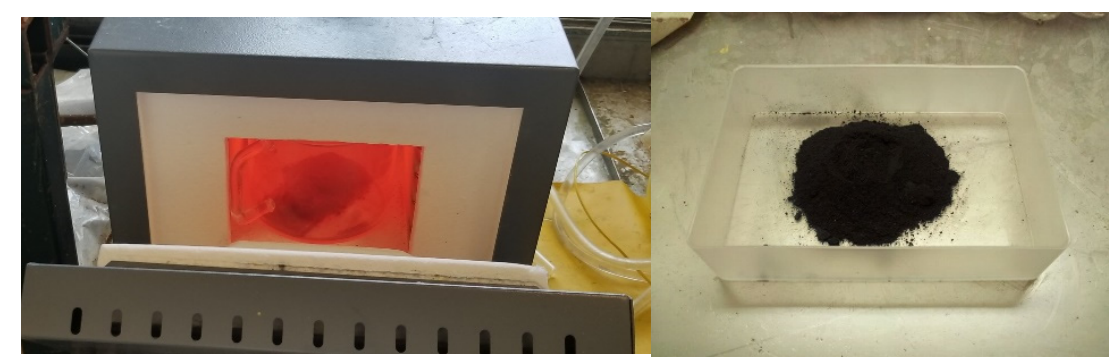

FIGURE 3 A 300-g batch of uranium mid-oxidation (left) and the completely oxidized batch (right).

TABLE 2 Particle size results from the batches of oxidized DU with a comparison to a batch of oxidized LEU.

\begin{tabular}{lrrrr}
\hline & \multicolumn{4}{c}{ Particle Size $(\mu \mathrm{m})$} \\
\cline { 2 - 5 } \multicolumn{1}{c}{ Experimental Batch } & $>400$ & $>105$ & $>63$ & $<63$ \\
\hline & & & & \\
4 - DU 50 g & 3.1 & 16.1 & 12.1 & 18.7 \\
5 - DU 50 g & 5.5 & 18.9 & 13.7 & 17.6 \\
6 - DU 50 g & 3.4 & 18.5 & 9.2 & 13.2 \\
& & & & \\
A - DU 300 g & 7.6 & 95.0 & 86.0 & 173.9 \\
B - DU 300 g & 5.0 & 73.4 & 81.1 & 177.2 \\
C - DU 300 g & 15.7 & 113.1 & 66.6 & 150.4 \\
& & & & \\
DU Average (g) & 6.7 & 55.8 & 44.8 & 91.8 \\
DU Percent (\%) & 3.4 & 28.0 & 22.5 & 46.1 \\
& & & & \\
LEU 50 g Weight (g) & 3.2 & 17 & 15.1 & 24.7 \\
LEU 50 g Percent (\%) & 5.3 & 28.3 & 25.2 & 41.2 \\
\hline
\end{tabular}




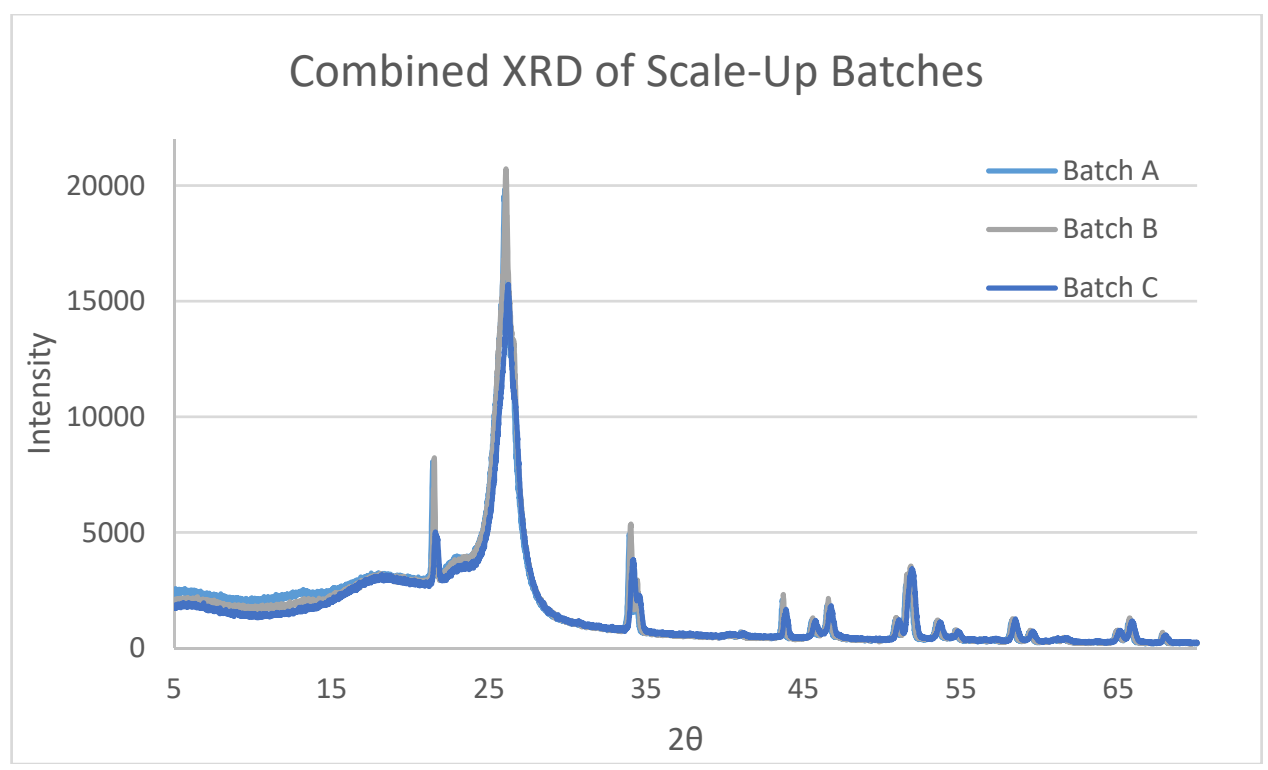

FIGURE 4 Powder X-ray diffraction analysis for the 300-g batches after oxidation.

The resulting spectra were verified to be $\mathrm{U}_{3} \mathrm{O}_{8}$ by matching to the program's internal library and the literature. This analysis revealed that we were getting complete conversion to $\mathrm{U}_{3} \mathrm{O}_{8}$ for each of the experiments, with no other major signals present in the spectra.

\subsection{DISSOLUTION OF $\mathrm{U}_{3} \mathrm{O}_{8}$}

After oxidation of $\mathrm{U}$ metal to $\mathrm{U}_{3} \mathrm{O}_{8}$ and determination of particle size distribution, dissolution using $\mathrm{H}_{2} \mathrm{O}_{2}$ and $\mathrm{H}_{2} \mathrm{SO}_{4}$ was performed. The oxidized material from the 300 - $\mathrm{g}$ batches was added to the digester system shown in Figure 5, while the 50-g batches were dissolved in 1-L beakers to test the different types of hydrogen peroxide.

First, 50-g U batches were used to test the effect of hydrogen peroxide. The Acros Organic, Fisher Chemical, and Millipore certificates of analysis were all nearly identical and they did not have any stabilizers listed on their product page. As expected, there was no noticeable difference among the three with respect to $\mathrm{U}$ dissolution. The reactions of all three showed nearly identical times for each stage of the dissolution. Because there was no detectable difference among the three manufacturers, the same lot of hydrogen peroxide (Fisher Chemical) was used for all $300-\mathrm{g}$-scale experiments. The reaction times of the dissolution experiments were also very consistent once we settled on a specific hydrogen peroxide manufacturer, as seen in Table 3. 


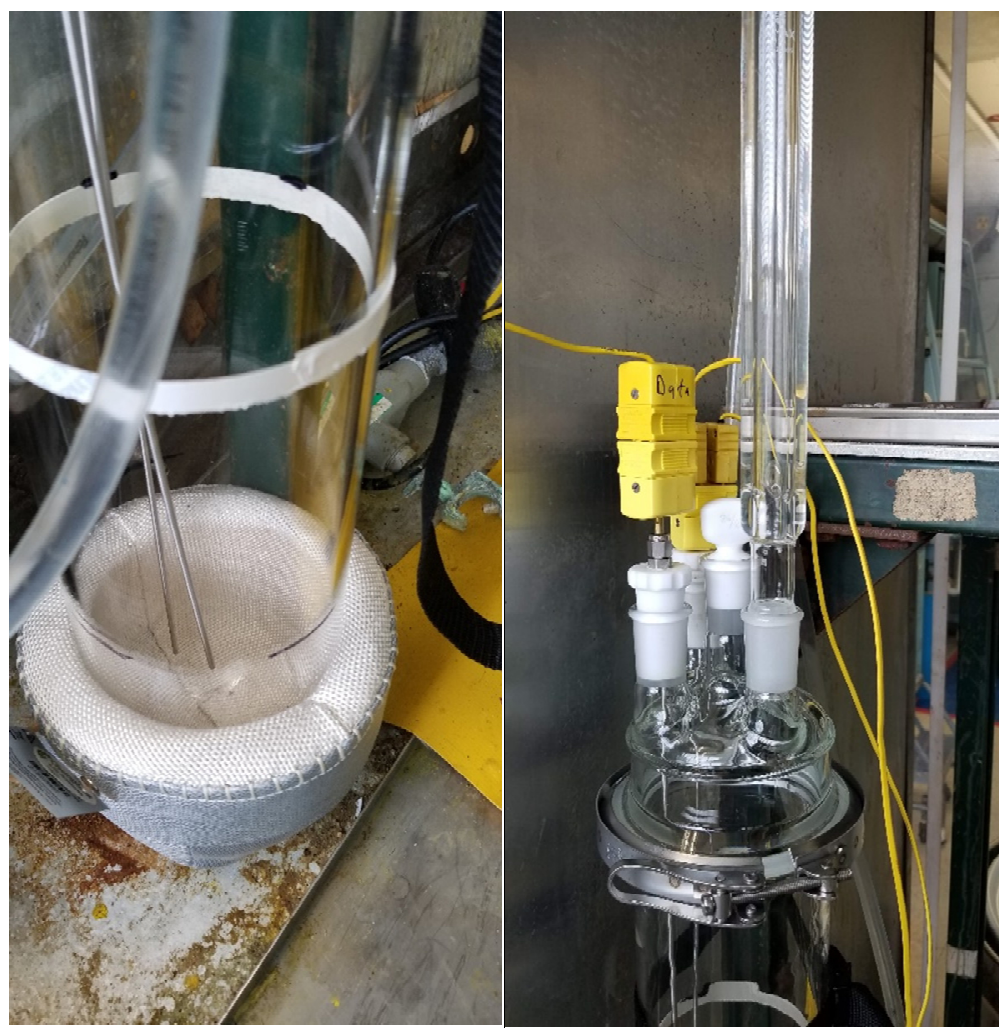

FIGURE 5 Bottom of the dissolution apparatus (left); top of the apparatus (right), with the thermocouple connections and condenser.

TABLE 3 Reaction times for the dissolution of $\mathrm{U}_{3} \mathrm{O}_{8}$ in hydrogen peroxide after the addition of sulfuric acid to the vessel.

\begin{tabular}{ccccc}
\hline $\begin{array}{c}\text { Experimental } \\
\text { Batch }\end{array}$ & $\begin{array}{c}\mathrm{H}_{2} \mathrm{O}_{2} \\
\text { Manufacturer }\end{array}$ & $\begin{array}{c}\text { Reaction } \\
\text { Time (min.) }\end{array}$ & $\begin{array}{c}\text { Turned to } \\
\text { Precipitate (min.) }\end{array}$ & $\begin{array}{c}\text { Turned to } \\
\text { Sulfate (min.) }\end{array}$ \\
\hline 1 & Fisher & 3 & 12 & 29 \\
2 & Acros & 3 & 12 & 29 \\
3 & Millipore & 3 & 11 & 29 \\
\hline
\end{tabular}

Before the dissolution, a water chiller connected to the condenser on top of the dissolution vessel was set to $5^{\circ} \mathrm{C}$ and a thermocouple was placed in the vessel to monitor the temperature during the reaction. When the setup was ready, hydrogen peroxide was added to the vessel containing $\mathrm{U}_{3} \mathrm{O}_{8}$. After a short wait time, concentrated sulfuric acid was added, and the reaction started immediately thereafter, as seen in Figure 6. 


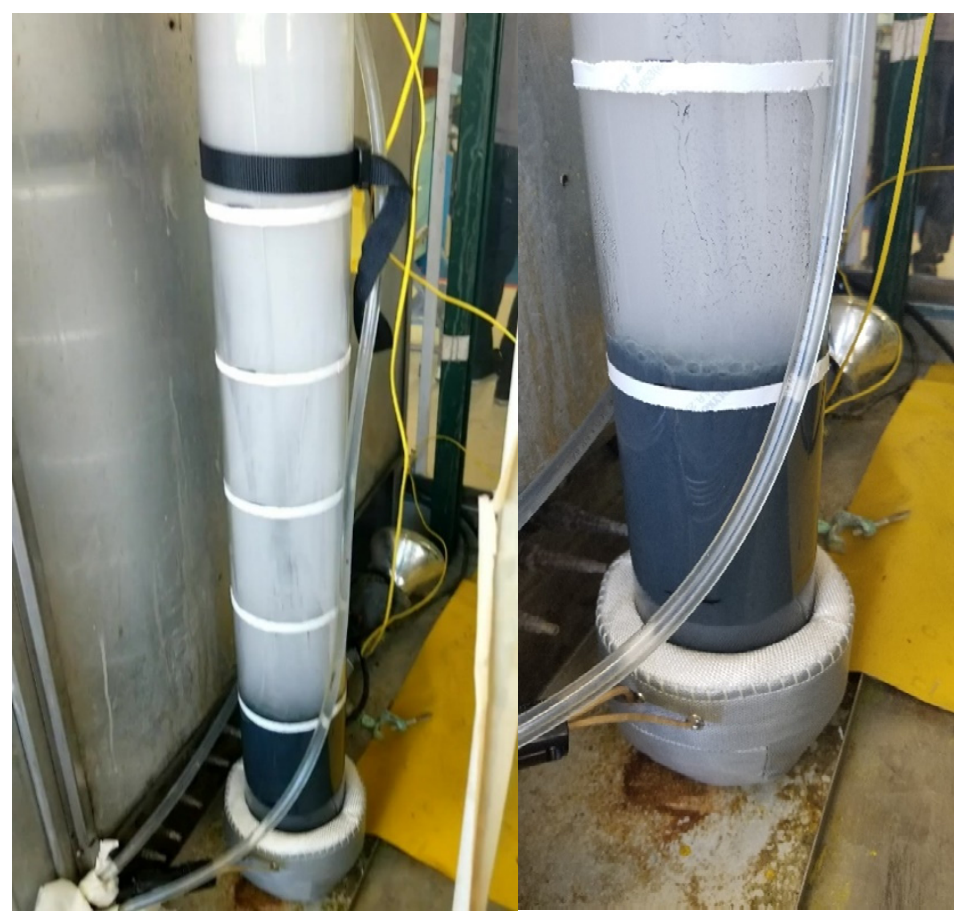

FIGURE 6 The beginning of the dissolution of uranium immediately after sulfuric acid was added to the hydrogen peroxide and uranium. The temperature quickly reached $99^{\circ} \mathrm{C}$, and the reaction at this stage was extremely vigorous.

The temperature ramped very quickly from room temperature up to nearly $100^{\circ} \mathrm{C}$ and the solution turned to a charcoal black, with vigorous bubbling The primary dissolution took between 15 and $20 \mathrm{~min}$ and the total processing time was 1-1.5 hours. The temperature profile of a typical dissolution experiment is shown in Figure 7.

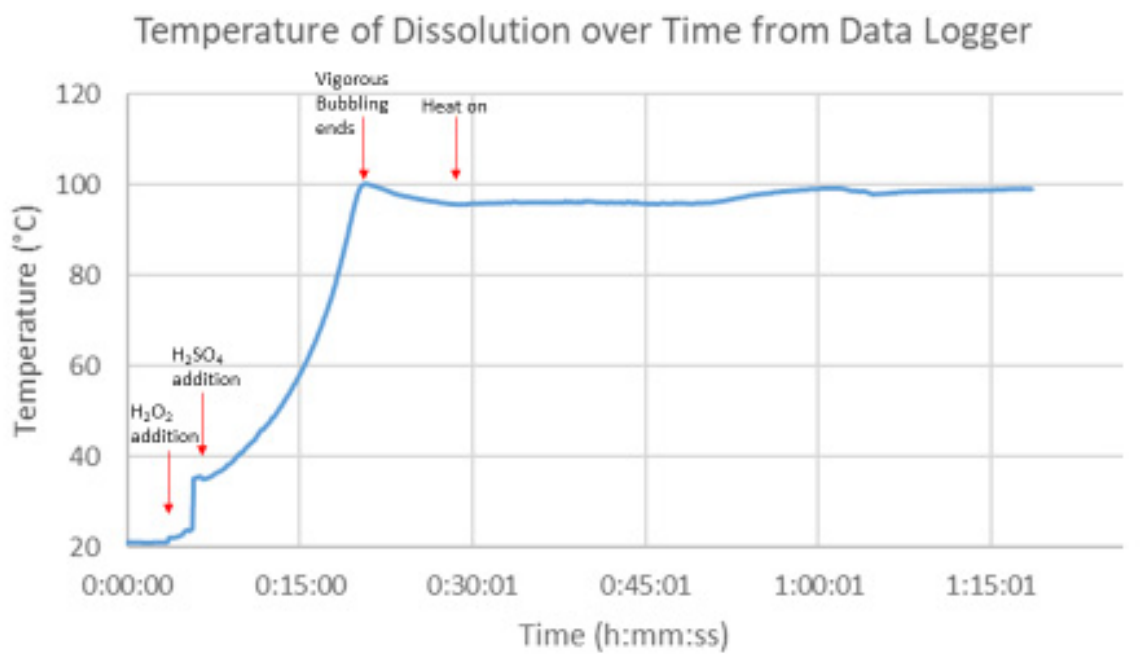

FIGURE 7 A typical temperature profile of a dissolution experiment. 
In Figure 7, the peroxide was added at $3.5 \mathrm{~min}$; the sulfuric acid was added at approximately the 6-min mark. The temperature quickly rose when the concentrated sulfuric acid was added to the reaction vessel, and the initial reaction lasted for $15 \mathrm{~min}$ (from 6 to $21 \mathrm{~min}$ in Figure 7). When the temperature started to drop at $21 \mathrm{~min}$, heat was added by turning on the heating mantle. The temperature in the vessel was controlled to stay between $95^{\circ} \mathrm{C}$ and $99^{\circ} \mathrm{C}$ for the remainder of the experiment, starting at $\sim 30$ minutes in Figure 7.

The solution bubbled and continued self-heating for approximately 15 minutes, as mentioned above and depicted in Figure 7, before it started to thicken and turn to a grey/green color as seen in Figure 8.
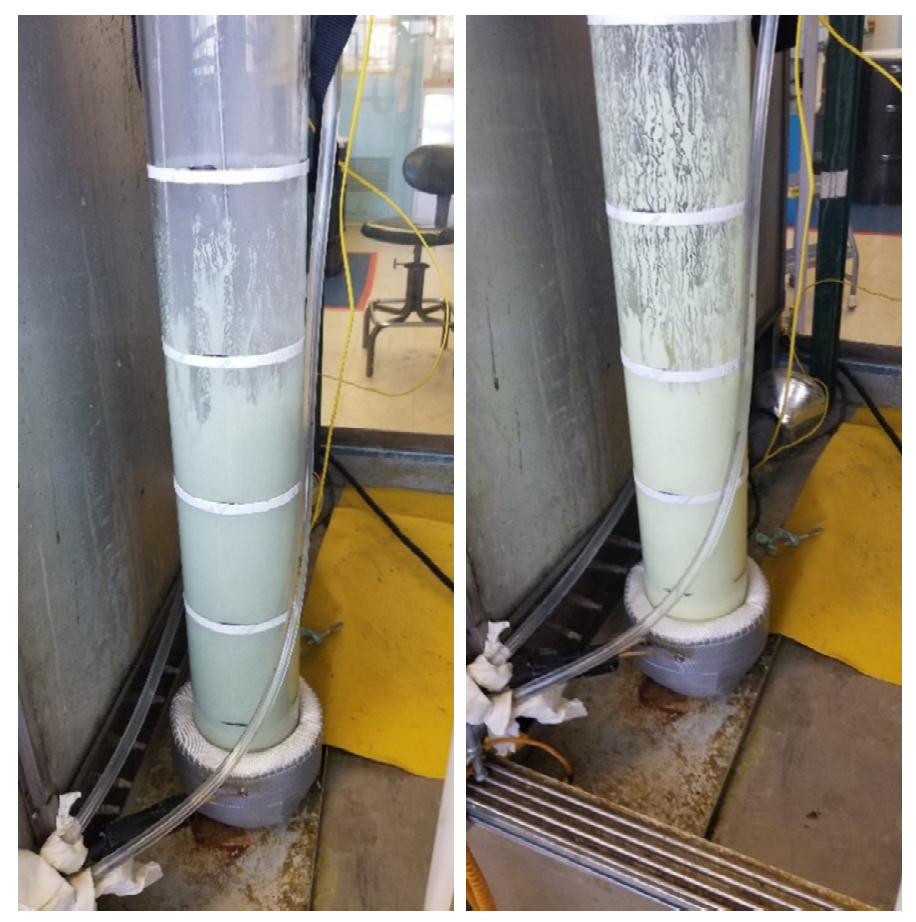

FIGURE 8 The transition from charcoal black to a gray/green color and a thickening of the solution, starting at $\sim 21 \mathrm{~min}$, is shown above. The temperature of the reaction also started dropping at this point, and heat was applied.

During this transition, the temperature of the reaction began to drop to $\sim 95^{\circ} \mathrm{C}$; therefore, heat was applied, with the thermostat adjusted to $99^{\circ} \mathrm{C}$. The solution volume also increased significantly during this phase; with a beginning volume of around $1.7 \mathrm{~L}$, the solution expanded as much as up to the 5-L mark of the reaction vessel. The reaction also burped frequently during this phase and coated the sides of the vessel with an occasional projection, making it to the lid of the reaction vessel near the condenser and thermocouple attachments. This phase continued for approximately 15 minutes before the reaction started to slow and the solution continued 
thickening while turning from the gray-green shown in Figure 8 to a light yellow color (Figure 9).

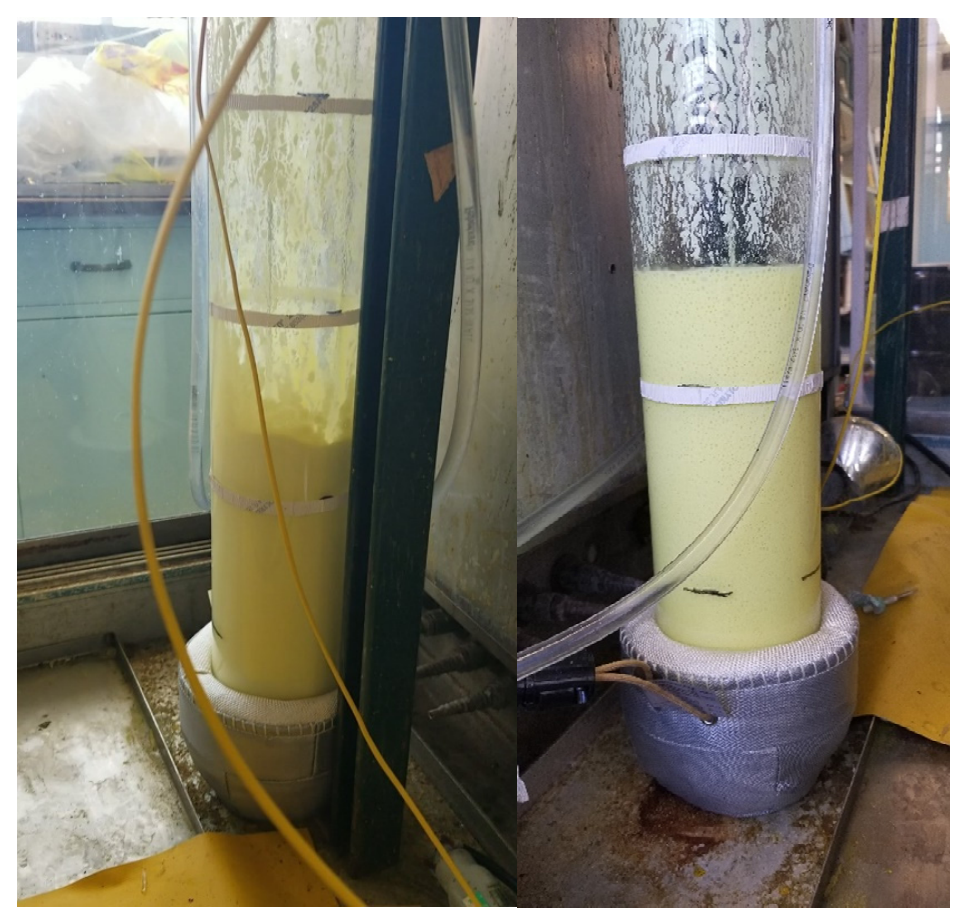

FIGURE 9 Approximately 35 minutes into the experiment, the reaction settled down from the vigorous stage, the solution turned more yellow, took on a foamy consistency, and started to "breathe."

After the color change to light yellow, the nature of the reaction changed from constant bubbling and burping to a more controlled "breathing," with the volume of the solution varying from about 2 to $3.5 \mathrm{~L}$. The thick solution also began to take on a more foamy consistency. With the vigorous reaction slowing down, we took this opportunity to rinse down the sides of the reaction vessel with water in an attempt to get the remaining residue on the sides of the vessel into solution for a complete dissolution. Within 5 to 10 minutes, the foamy solution mixture switched to a liquid consistency with a deeper yellow color and looked more like orange juice, as depicted in Figure 10. 

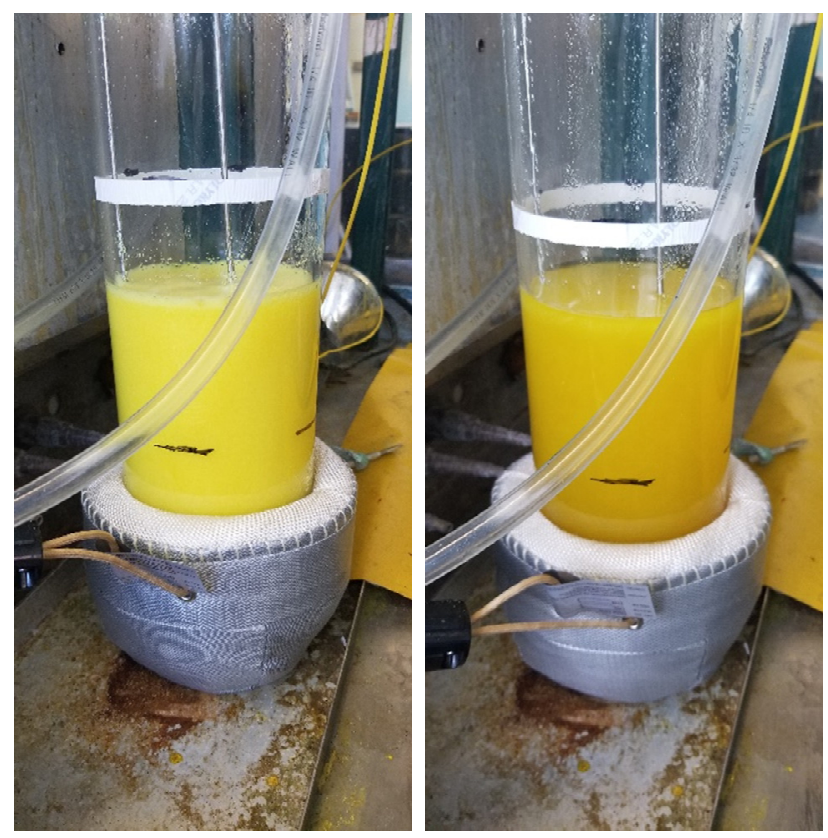

FIGURE 10 The foamy mixture transitioned to a more traditional liquid 40 to 45 minutes into the experiment and began to clear.

Upon the transition to a deeper yellow, the foam continued to clear and the solution volume dropped back to about $1.7 \mathrm{~L}$. It was also at this point that the solution started to go from completely opaque to a more translucent state. Within 5-10 minutes, the solution became transparent and a deep gold color, as shown in Figure 11. Heating continued until fizzing of the solution stopped, which indicated complete destruction of excess peroxide. 


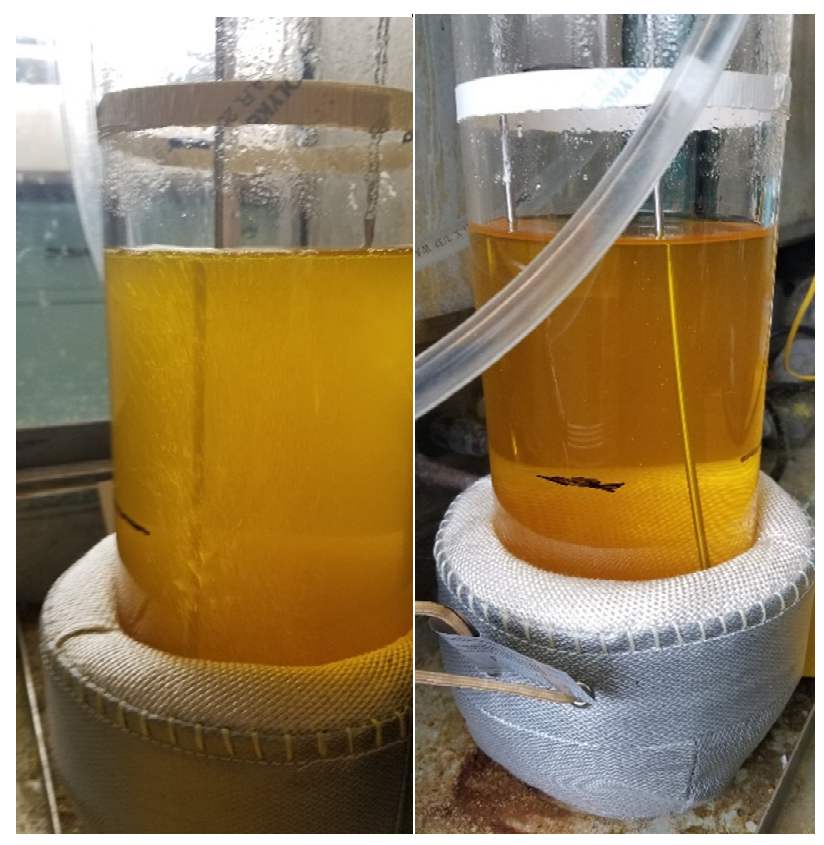

FIGURE 11 The solution turned completely clear and became the desired uranyl sulfate solution after reacting for approximately an hour.

The resulting uranyl sulfate solution was allowed to cool to room temperature before being transferred to another vessel. The dissolution apparatus was inspected after each run and little residue was found left behind in the reaction vessel. A small amount of residue, which is typically less than a few grams for a 300-g batch of U, can be seen in Figure 12.

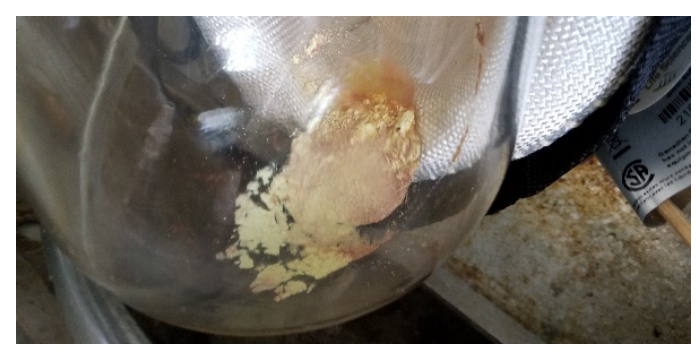

FIGURE 12 A small amount of residue left behind from the dissolution process.

On visual inspection, no black powder remained in the residue, indicating that the conversion to $\mathrm{U}_{3} \mathrm{O}_{8}$ was complete. This supposition was confirmed via XRD: a sample of the residue was analyzed, and only $\mathrm{U}_{3} \mathrm{O}_{8}$ was observed in the spectrum. The weight of the residue was estimated to be $<5$ grams. 


\section{CONCLUSION}

$30 \%$ hydrogen peroxide solutions from three different manufacturers were tested, and no significant difference in the dissolution behavior of $\mathrm{U}_{3} \mathrm{O}_{8}$ was observed. Since the reaction times were nearly identical, price or availability of the hydrogen peroxide could be the basis for determining which manufacturer should be used. For consistency, the Fisher brand was used for all additional experiments. Furthermore, we determined that the particle size distribution of $\mathrm{U}_{3} \mathrm{O}_{8}$ obtained after oxidation of all $\mathrm{U}$ metal batches was very consistent, regardless of the starting $\mathrm{U}$ metal form (plates vs. pellets). It was also observed that the time for each phase of the dissolution process was consistent for all $300-\mathrm{g} U$ batches, with a total processing time between 1 and $1.5 \mathrm{hr}$ when Fisher Chemical 30\% hydrogen peroxide was used. The results showed nearcomplete dissolution of the $\mathrm{U}_{3} \mathrm{O}_{8}$, and the small amount of residue left behind was confirmed to be $\mathrm{U}_{3} \mathrm{O}_{8}$ that was not completely dissolved and converted to uranyl sulfate. The residue could be added to future batches to prevent loss of material in large-scale operations. 



\section{Argonne}

\section{Chemical \& Fuel Cycle Technologies Division}

Argonne National Laboratory

9700 South Cass Avenue, Bldg. 205

Lemont, IL 60439-4832

www.anl.gov 